\title{
Simulation models applied to practical learning and skill enhancement in direct and indirect ophthalmoscopy: a review
}

\author{
Modelos de simulação aplicados ao ensino prático e aprimoramento de habilidades em oftalmoscopia \\ direta e indireta: uma revisão
}

Lucas Holderegger Riccl ${ }^{1}$, Caroline Amaral Ferraz ${ }^{1}$

\begin{abstract}
The purpose of this review was to analyze and describe simulation methods for practical learning and training of the ophthalmoscopy exam and to organize them into specific topics relative to each principle of operation, while evaluating their preliminary results. A critical review of articles that described and evaluated simulated models for ophthalmoscopy published in the last ten years (2004-2014) was performed. One hundred articles about ophthalmology and simulation were found in national and international periodicals, but only a few discussed the examination of the posterior pole of the eye. For this study, 25 articles were considered; those articles described simulation methods, general concepts, and its actual use in ophthalmoscopy. There were many different simulation methods described, but only few articles proved their efficacy or performed a comparison between models. Review of this topic may give information for the critical analysis of the simulation devices and ideas for the development of new ones.
\end{abstract}

Keywords: Ophthalmoscopy/methods; Education, medical/methods; Models, educational; Clinical competence

\section{RESUMO}

O objetivo desta revisão foi analisar e descrever os métodos de simulação, apresentados em um conjunto de artigos, sobre o ensino prático e treinamento no exame de oftalmoscopia e organizá-los em tópicos específicos, referentes aos seus princípios de funcionamento, avaliando resultados preliminares. Uma revisão crítica de artigos que tratam sobre modelos de simulação para oftalmoscopia que foram criados nos últimos dez anos (2004-2014) foi realizada. Após a análise de 100 artigos, encontrados emperiódicos nacionais einternacionais, sobre oftalmologia esimulação, percebemos o pouco material existente em relação ao exame de fundo de ol ho. Para este estudo, apenas 25 foram considerados, os quais descrevem métodos de simulação, conceitos gerais eseu uso atual na oftalmoscopia. Vários métodos de simulação jáforam descritos, mas poucos artigos provam sua eficácia ou realiza uma comparação entre diferentes modelos. Uma revisão deste tópico pode contribuir para possiveis análises críticas de dispositivos de simulação já existentes e ideias para criação de outros.

Descritores: Oftalmoscopia direta; Oftalmoscopia indireta; Habilidades; Simulador; Modelos de simulação

\section{INTRODUCTION}

The ophthalmoscopy exam is a simple and efficient method for the diagnosis of many conditions, although its full domain is often weak by most individuals in the medical community ${ }^{(1,2)}$. In general, this weak proficiency has depended on specific factors, like insufficient training leading to low confidence ${ }^{(3,4)}$, lack of interest in ophthalmo$\log y^{(5)}$, and a decrease in the regular use of the traditional ophthalmoscope ${ }^{(6,7)}$ in medical students and general physicians.

The direct ophthalmoscope is "a small, portable, and simple to comprehend" tool(8) and can be used to assist the examiner in discovering several pathological conditions, even those that are not directly associated with the eye ${ }^{(9)}$. For its importance, the direct ophthalmoscope has even been recommended to be a routine tool in daily medical practice, like the stethoscope, sphygmomanometer, and reflex hammer ${ }^{(10)}$

The low quality of direct ophthalmoscopy (DO) by most individuals, as stated before, has improved since the new simulation methods have been created. Simulation creates opportunities ${ }^{(11,12)}$, and it has increasingly been adapted to medical school teaching. It can utilize several different methods to improve skills, such as mannequins, task-specific training, simulated patients, and computer simulation ${ }^{(13)}$, and bring practical learning proximal to the real situation.

\section{METHODS}

The critical literature review included the articles that had been published in the main periodicals about different equipment and methods of simulation developed in the last ten years (2004-2014) that had been applied to the ophthalmoscopic exam. The following databases were considered for consultation: PubMed, Scielo, BVS, LILACS, Medline, BIREME, and Capes. After a period, we organized the presented material in order to obtain studies that described (1) actual practice of simulation in medicine, (2) evaluation of the ophthalmoscopy practical teaching in general, and (3) simulated methods developed for this exam. One hundred articles that covered one of the topics specified above were found and considered for this study; only 25 matched all criteria. We included articles in both Portuguese and English. The keywords used were Ophthalmoscopy, Simulator, Skills, Tools, and Evaluation.

\section{RESULTS AND DISCUSSION}

There have been only a few simulation methods applied to the ophthalmoscopy exam. When only considering studies from the last ten years, this number was even smaller, precisely because of the short period of time involved in this analysis. Regardless of this versities.

Medical School, Universidade Anhembi Morumbi, Laureate International Universities, São Paulo, SP, Brazil.

Funding: No specific financial support was available for this study.

Disclosure of potential conflicts of interest: None of the authors have any potential conflicts of interest to disclose.

Corresponding author: Lucas H. Ricci. Rua Dr. Almeida Lima, 1.134 - São Paulo, SP - 03164-000 Brazil - Email: lucholder@hotmail.com 
fact, some methods may be very promising and vary from rudimentary techniques to high tech mechanisms, and they are described hereafter.

Indirect ophthalmoscopy $(\mathrm{IO})$ is a more complex exam than DO, and its use is reserved for ophthalmologists and specialized professionals. Nevertheless, as the literature has presented us with some simulation techniques for this method, we described the skills and simulator equipment for this exam as well. For better organization, they were separated into specific topics, relative to each principle of operation.

\section{DiRECT OPHTHALMOSCOPY SIMULATORS}

For this type of exam, we found four possible models with and without scientific approval. Those were the Plastic Canister model, THELMA, Eye Exam Simulator, and VRmagic Simulator.

\section{Plastic Canister model}

In 2004, Chung and Watzke ${ }^{(14)}$ described a simple and cheap model that allowed the simulated evaluation of the posterior pole of the eye with a traditional direct ophthalmoscope. It consisted of a device, a plastic canister, which had an 8 millimeter hole in the center of one end, which represented the dilated pupil of the patient. In the other end, a photographic picture of the fundus was placed internally, and resized and shaped in a circle format by the edition program Adobe Photoshop (Adobe Systems, Washington) in miniatures of $37 \mathrm{~mm}$ to simulate the retina. In 2009, Hoeg ${ }^{(15)}$ applied this model in a research project involving second-year graduate students at the Medical College of Wisconsin, using normal pictures of the fundus, as well as photographs of diabetic retinopathy, papilledema, and glaucoma. In this experiment, a series of linear words with low visualization (font-size: 3.28) was set in a way that they simulated the blood vessels in the retina. If the student was able to read these words properly, the investigator would then use the device with the true photographs. After the analyses of the performed tests, it was observed that $89.9 \%$ of the students confirmed that the utilized method was easy to handle, and $75.8 \%$ confirmed that the device enhanced the quality of their learning. In 2011, another study ${ }^{(16)}$ used Chung and Watzke's model with a slight modification. In this case, it also utilized plastic canisters with $3 \mathrm{~mm}$ holes to represent the pupil in its non-dilated aspect, unlike the $8 \mathrm{~mm}$ model. For the evaluation, the canister was used pre-and post-test with pre-determined parameters to establish the level of accuracy of visualization in the procedure. In general, students that obtained a grade worse than $90 \%$ in the pre-test had a significant increase after training with the device (pre-test: $47 \%$, post-test: $86 \% ; p=0.0001$ ). Although Hoeg had recommended some modifications, like high-quality photos, matte paper for the printing of the pictures, and indications for the nose of the patient in the device, this method seemed to demonstrate efficient results for the initial practice of ophthalmoscopy.

\section{THELMA}

Simultaneously, with the ascendance of new technological materials, at the end of 2007, $\mathrm{PaO}^{(17)}$ built a Styrofoam head in order to utilize two methods to evaluate the retina. Originally called THELMA (The Human Eye Learning Model Assistant), this model used equipment that could display photographs in one eye (Slide Method), and an apparatus similar to an eyeball, or a plug, in the other (Plug Method). In the first, the images of the retina were displayed by the equipment and positioned through the coronal temporal region of the head, so they could be placed exactly in the posterior part of the eye of the model. The second method used a little plug that was shaped like the human eye with a diameter of $17 \mathrm{~mm}$ so that the field of vision can widen to 60 degrees at the opening when visualized with a direct ophthalmoscope. The image of the retina was placed in the back of the plug, and resized to its natural format to make it as real as possible.
The Slide Method presented a better view of the images (illumination through the equipment) and higher size of the true retina, while the Plug Method presented real-size photographs, bringing more reality to the device; however, the amount of light depended on the ophthalmoscope and the quality of the paper, since the latter could cause reflection problems. Each method demonstrated a particular specificity and both should be used together, but there still has been a lack of scientific reports on the effectiveness of this model.

\section{Eye exam Simulator}

In 2009, McCarthy ${ }^{(18)}$ performed a survey using the simulation model EYE Exam Simulator (originally created by Kyoto Kagaku Co.), with a few modifications. It was built in a designed head with adjustable pupils and removable photographs measuring $35 \mathrm{~mm}$ placed at the interior part of the eye; these pictures simulated the retina, and could be visualized through a traditional hand-held ophthalmoscope (Figure 1). Images with positioned letters were used in the four corners of the field of view to evaluate if the person was observing the fundus correctly; once the letters were able to delimitate the visible part of the picture. The research, performed with 11 ophthalmology residents and 46 emergency medicine (EM) residents, demonstrated that, in general, the model did not significantly improve the confidence and skills of both types of residents. Some hypotheses have been suggested for the inefficiency of this simulator, including the eccentric position of the four letters in the image, darker pictures with low illumination, and the preference for 10 by ophthalmologists. However, a recent 2014 study by Larsen ${ }^{(19)}$ using second-year students over four years, showed promising results when utilizing the same model of simulation, but with different factors than McCarthy's version. Beyond the similar usage of the device, an instructor was present to assist the student during the training, and at the end of the procedure, the instructor asked the student to point to the image that he/she had visualized in the simulator; therefore, the instructor was certain that the student used the correct practice. As a result, out of the $64 \%$ of the second-year students (general average of the four years of research), $98 \%$ confirmed that practice with the model helped them with real patients during their later years. Another fact that confirmed the impact of the assistant instructor with the EYE Exam Simulator was that when it was suggested that the students should train themselves during the third year of the research, fewer of them applied to the study program $(12 / 113 ; 11 \%)$; however, during the other three years, the numbers were much higher (Year 1:68/115, Year 2: 77/119, Year 4: 88/127).

The previous results showed that, even if the simulator represented high-quality technology, its use can bring complaints and frustration when not assisted by an experienced person or if the student did not receive detailed instructions on how to use the device.

\section{VRMAGIC SIMULATORS}

On a more technological level, the company for simulation equipment, VRmagic, recently created a series of products for ophthalmology procedures. Among those, the ones for ophthalmoscopy can be highlighted. Considering that the product represented the two possible types of ophthalmoscope (direct and indirect), the first one has been described first, and the second will be described later in the paper. Both of them are shown in figure 2.

The EYEsi Direct Ophthalmoscope Simulator ${ }^{(20)}$ was a highly specific device, developed for a better and more real response during the ophthalmoscopy exam. It consisted of a touch-screen computer attached to a simulated real-size human face, allowing the examiner to evaluate the normal and pathological fundus with an also-attached hand-held ophthalmoscope. When compared with other simulated means, like training with a real person or using printed photographs, this model possessed unique advantages: special screen for mapping the visualized areas (for better localization), control of the technical and physiological aspects (light, color of the blood vessel, pathological spots, occlusion) at several possible levels, immediate 

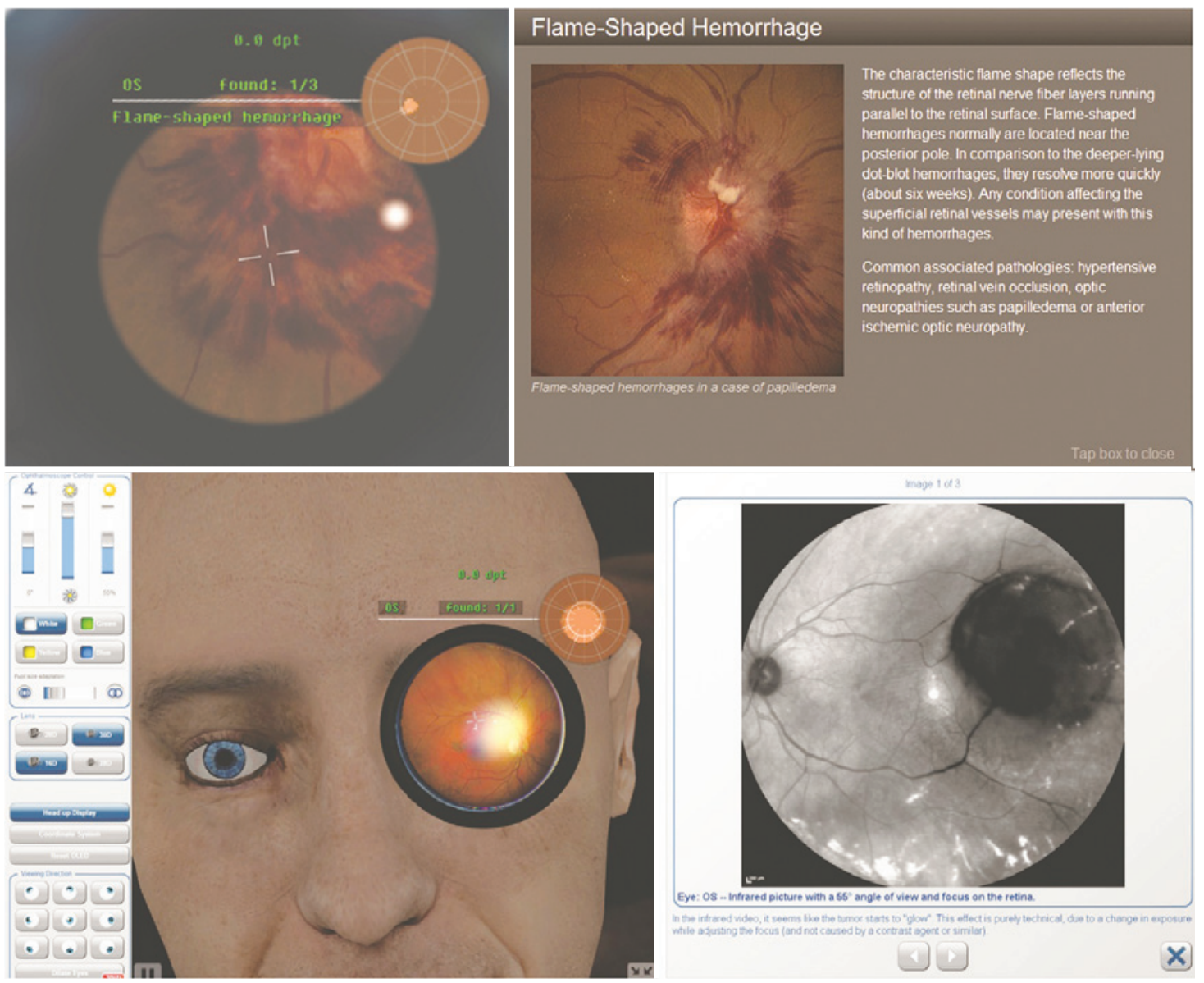

Figure 1. EYE Exam Simulator by Kyoto Kagasu Co.

feedback after the exam (showing the examiner his errors and qualities), and information about altered pictures. This kind of simulator also integrated photoreagent pupils and spontaneous venous pulsation to make the exercise as real as possible. Unfortunately, it is a newer and more expensive model, and does not have comparative studies that have proven its efficacy.

\section{INDIRECT OPHTHALMOSCOPY SIMULATORS}

Similar to the previous topic, we now have listed three models of IO simulation: Eyeball model, Plastic Canister Model, and VRmagic Simulator. For all of these types, none have presented actual evidence or studies regarding its efficacy.

\section{Eyeball MOdel}

In 2006, Lewallen ${ }^{(21)}$ presented an easy and inexpensive model for $1 \mathrm{O}$ training. It was built with a round glass sphere placed in a deep surface that would keep its immobility. In this case, a Styrofoam piece was used. Between the glass and the surface, a paper with small letters (package inserts from prescription medicine is a good example) was positioned in a way that the sphere was half-covered. Finally, a hole was made in a piece of paper that served as the pupil, and it covered the entire set. This model aimed to teach the correct placement of the convergent lens and the light, so the examiner can begin to understand the basic principles of $\mathrm{IO}$. No comparative studies or evaluation methods, however, have been applied to this model.

\section{Plastic Canister model}

Similar to the device created by Chung and Watzke, Lantz ${ }^{(22)}$ used the same principle of simulation to create a method for the indirect exam in 2009. Originally, his idea was focused on pathologists for examination of the fundus during the autopsy (for the post-mortem period). The central hole which represented the pupil in this case measured $9 \mathrm{~mm}$ and the evaluation of the fundus required a flashlight, attached to a helmet, and a convergent lens, that allowed the expansion of the image in all possible fields of view. Although it was developed for use in autopsies, there is no reason that it cannot be adapted to training for the care of living patients.

\section{VRMAGIC SIMULATOR}

As stated before, the company VRmagic also developed an 10 simulator. With a higher technologic complexity, the EYEsi Indirect Ophthalmoscope Simulator ${ }^{(23)}$ allowed performance of the training exam with various mechanisms. Compared to the DO simulator, created by the same company, this model also used a specific computer for general control of the procedure, and was placed the same molded human face. The exam was performed with an attached helmet that aimed a beam of light in a movable lens, which had to be correctly positioned in the eye of the simulated face. The retina then was visualized through the helmet and displayed on the computer, where it could be manipulated and edited; this allowed a better comprehension and understanding of skills required for training. The 


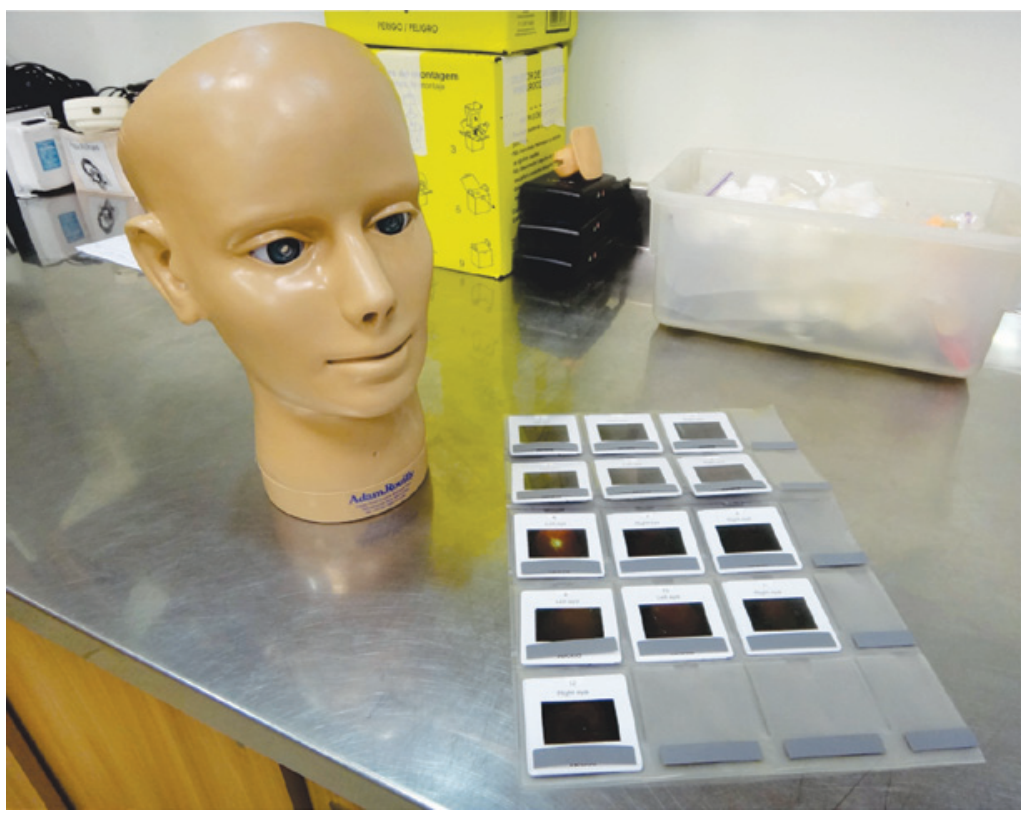

Figure 2. Ophthalmoscopy simulators developed by VRmagic. Direct model at the top and Indirect model at the bottom.
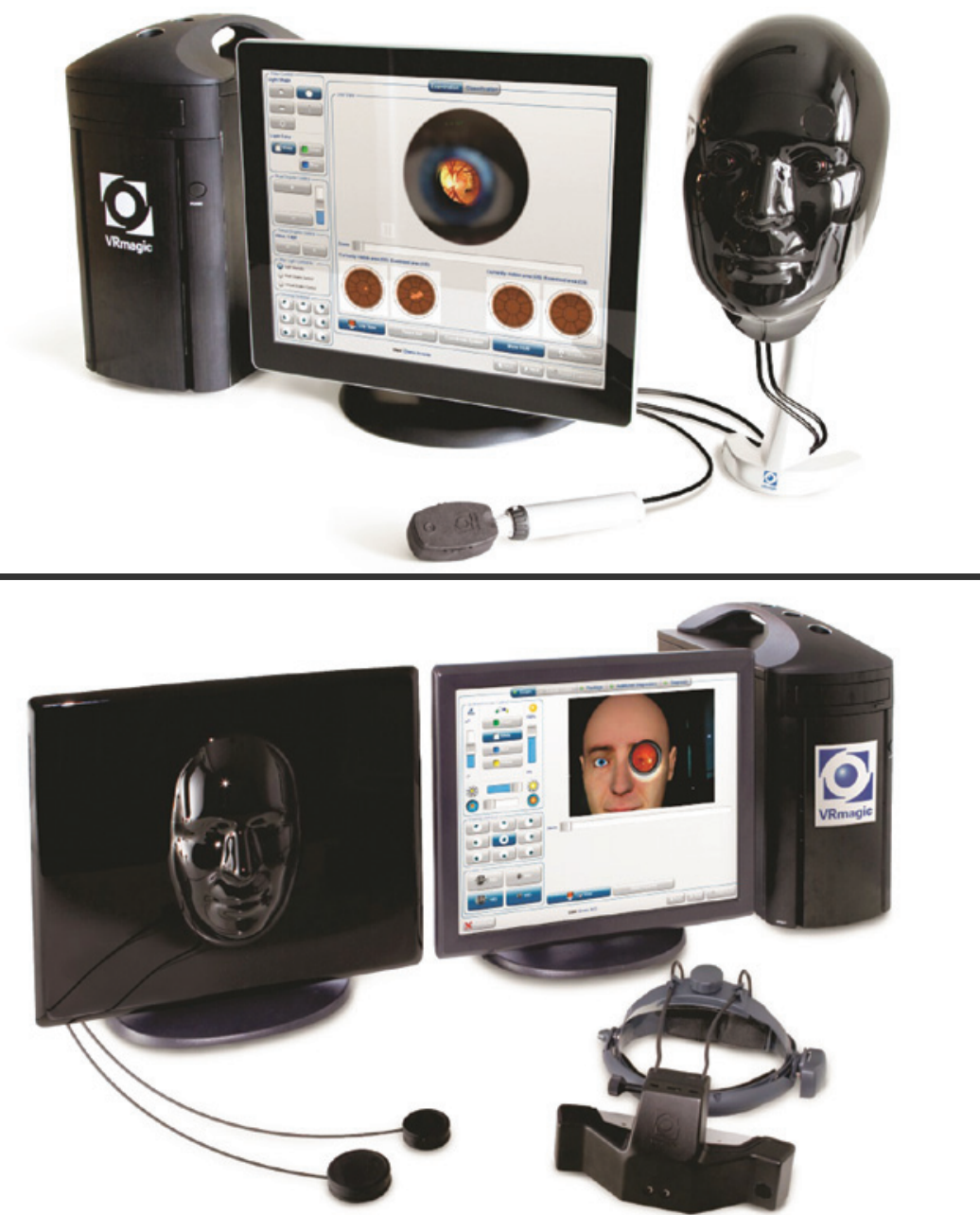

Figure 3. Image examples and software appearance of the Direct model (at the top) and Indirect model (at the bottom). 
model presented clinical cases based on real events with a specific demonstration to guide the light and lens position and several normal and pathological fundus images; after each exam, the feedback displayed the good or bad performances and any aspects worth changing. Some examples of the program and photos are shown in figure 3, along with images from the direct model.

\section{CONCLUSION}

As far as we know, there has been no other article in literature concerning a review of ophthalmoscopy methods with a simulation approach. Most of the articles only described a model or compared the efficiency separately.

The simulation can be a helpful tool both in ophthalmoscopy training and learning, once researchers develop a better understanding of its true benefits. A few aspects, however, must be considered for the full use of simulators in practical learning. The high cost of some machines require that the training has to be implemented in a determined place ${ }^{(11)}$ and some individuals learn better with pathologic photographs of the retina rather than the whole simulator (24). Furthermore, the quality level of the simulation must be controlled and adapted for each person, since the excess of realism and complexity can confuse the examiner when learning basic skills, as shown by medical students ${ }^{(25)}$. Also, the constant training in with this equipment may cause the physician or student to forget the procedures and protocols developed to guarantee the safety and comfort of the examined patient.

Although some methods can present a high degree of expertise, there has been a lack of studies that can verify the efficacy of the various models. Some may be relatively new and, while presenting all necessary mechanisms for a complete simulated exam, do not possess proven efficiency at a scientific level.

\section{REFERENCES}

1. Wu EH, Fagan MJ, Reinert SE, Diaz JA. Self-confidence in and perceived utility of the physical examination: a comparison of medical students, residents, and faculty internists. J Gen Intern Med. 2007; 22:1725-30.

2. Holmboe ES. Faculty and the observation of trainees' clinical skills: problems and opportunities. Acad Med. 2004;79:16-22.

3. Gupta RR, Lam WC. Medical students' self-confidence in performing direct ophthalmoscopy in clinical training. Can J Ophthalmol. 2006:41:169-74.
4. Shuttleworth GN, Marsh GW. How effective is undergraduate and postgraduate teaching in ophthalmology? Eye (Lond). 1997;11(5):744-50.

5. Lopes Filho JB, Leite RA, Leite DA, de Castro AR, Andrade LS. Avaliação dos conhecimentos oftalmológicos básicos em estudantes de Medicina da Universidade Federal do Piauí. Rev Bras Oftalmol. 2011;70(1):27-31.

6. Morad Y, Barkana Y, Avni I, Kozer E. Fundus anomalies: what the pediatrician's eye can't see. Int J Qual Health Care. 2004;16(5):363-5.

7. Lippa LM. Ophthalmology in the medical school curriculum: reestablishing our value and effecting change. Ophthalmology. 2009;116(7):1235-6.

8. Sit M, Levin AV. Direct ophthalmoscopy in pediatric emergency care. Pediatric Emergency Care. 2001;Jun 17(3):199-204

9. Asman P, Lindén C. Internet-based assessment of medical students' ophthalmoscopy skills. Acta Ophthalmologica. 2010;Dec, 88(8):854-7.

10. Seidel HM, Ball JW, Dains JE \& Benedict GW (2006): Mosby's guide to physical examination, $6^{\text {th }}$ Edn. Mosby: Elsevier.

11. Weller JM, Nestel D, Marshall SD, Brooks PM, Conn JJ. Simulation in clinical teaching and learning. Med J Aust. 2012;196(9):594.

12. Benbassat J, Polak B C P, Javitt J C. Objectives of teaching direct ophthalmoscopy to medical students. 2012. Acta Ophthalmologica, 90:503-7.

13. Labuschagne, MJ. The role of simulation training in ophthalmology. Continuing Medical Education, v. 31, n. 4, p.157-159, mar. 2013

14. Chung KD, Watzke RC. A simple device for teaching direct ophthalmoscopy to primary care practitioners. Am J Ophthalmol. 2004;138:501-2.

15. Hoeg TB, Sheth BP, Bragg DS, Kivlin JD. Evaluation of a tool to teach medical students direct ophthalmoscopy. WMJ. 2009;108:24-6.

16. Swanson S, Ku T, Chou C. Assessment of direct ophthalmoscopy teaching using plastic canisters. 2011. MEDICAL EDUCATION. 2011;45:508-35.

17. Pao KY, Uhler TA, Jaeger EA. Creating THELMA - The Human Eye Learning Model Assistant. Journal of Academic Ophthalmology. 2008;1:25-9.

18. McCarthy DM, Leonard HR, Vozenilek JA. A new tool for testing and training ophthalmoscopic skills. J Grad Med Educ. Mar 2012;4(1):92-6.

19. Larsen, P, Stoddart, H. and Griess, M. (2014), Ophthalmoscopy using an eye simulator model. The Clinical Teacher, 11:99-103.

20. VRmagic Co. Direct Ophthalmoscope Simulator. http://www.vrmagic.com/fileadmin/ downloads/simulator_brochures/Eyesi_Direct_Brochure_131029_EN_WEB_DP.pdf [Accessed April 20, 2014]

21. Lewallen S. A simple model for teaching indirect ophthalmoscopy. Br J Ophthalmol. Oct 2006;90(10):1328-9.

22. Lantz PE. A simple model for teaching postmortem monocular indirect ophthalmos copy. J Forensic Sci, May 2009, Vol. 54, №. 3

23. VRmagic Co. Indirect Ophthalmoscope Simulator. http://www.optotechnik.com ve/_catalogos/vrmagic_eyesi_indirect-brochure.pdf [Accessed April 21, 2014]

24. Kelly LP, Garza PS, Bruce BB, Graubart EB, Newman NJ, Biousse V. Teaching Ophthalmoscopy to Medical Students (the TOTeMS Study). 2013. American Journal of Ophthalmology, Volume 156, Issue 5, 1056-1061.

25. Lippa LM, Boker J, Duke A, Amin A. A Novel 3-Year Longitudinal Pilot Study of Medical Students' Acquisition and Retention of Screening Eye Examination Skills. American Academy of Ophthalmology. Jan 2006. Vol. 133, Issue 1, p.133-139. 